\title{
Sound Transmission Loss Analysis on Building Materials
}

\author{
W. H. Tan* and C. F. Sin \\ School of Mechatronic Engineering, Pauh Putra Campus, Universiti Malaysia Perlis \\ (UniMAP), 02600 Arau, Perlis, Malaysia \\ *Email: whtan@unimap.edu.my \\ Phone: +6049885282; Fax: +6049885167
}

\begin{abstract}
This study is mainly to determine the sound transmission loss (STL) performance of the four selected building materials using the impedance tube. The four building materials are; autoclaved aerated concrete (AAC), laminated glass, expanded polystyrene and rockwool. Transmission loss occurs when a sound goes through a partition or barrier. The specimens are prepared in two thicknesses, which are $10 \mathrm{~mm}$ and $20 \mathrm{~mm}$. The STL of the specimen was determined and analysed. It is observed that the STL results for all the tested materials are having a similar trend, which is a thicker specimen gives higher STL. In general, all the materials deliver high STL at the frequency range of $3000-5500 \mathrm{~Hz}$. In overall, the result shows that the expanded polystyrene scores the highest STL among the four building materials in this study. Six combinations of different material also were tested, and AAC \& expanded polystyrene combination shows the highest STL value among the six combinations. The outcomes of this study can be referred by noise control engineer on the selection of the sound insulation material for the building noise insulation treatment.
\end{abstract}

Keywords: Sound transmission loss (STL); building materials.

\section{INTRODUCTION}

Acoustic knowledge on the building material is important when it comes for construction. It is important to know what the desired requirement of the wall is and which materials suitable for it [1]. People often made a mistake in choosing the noise insulation material for the buildings and resulted in too much echo during the speech in the hall or etcetera [2-3]. The basic knowledge on the acoustic is the sound transmission loss (STL) and sound absorption. These two terms may sound like the same, but it is not. The STL occurs when a sound goes through a partition or barrier [4]. When airborne sound impinges on a wall, some of the sound energy is reflected, some energy is absorbed within the wall structure, and some energy is transmitted through the wall [5]. Whereas the sound absorption is the act of turning acoustical energy into some other form of energy, usually is heat. The sound insulation performance of the noise insulation materials depends on the thickness, density, and others [6].

Normally, the parts of a building, such as roof, wall, door and window are required specific acoustic property to achieve sound insulation purposes, for instance, insulate the traffic noise, construction noise, and machining noise which the noise source nearby with the residential area [7]. The target materials for this study are wall materials, which are Autoclaved Aerated Concrete (AAC), laminated glass, expanded polystyrene and rockwool as normally these materials are used for the building wall or partitioning of the 
rooms. For example, AAC widely to be used for wall building as it is cost-effective [8], good sound insulation [9-10], and lightweight [11].

In general, heavy and impervious materials are shown better in blocking or attenuating sound energy compare to light and porous materials. The empirical mass law deduced from real-world measurements showed that the transmission loss is directly proportional to the surface density of the barrier [4]. Thus, different types of wall materials are selected and analysed to determine the STL performance in this study.

\section{METHODOLOGY}

\section{Two-load Method}

The two-load method is one of the methods to determine the sound pressures and from the sound pressures calculate the sound transmission loss (STL). Figure 1 shows the sketch of the two-load method STL impedance tube measurement. For the STL impedance tube measurement, there are four sound waves transmitted from the sound source, passing through the specimen, and sound waves reflected by the specimen and rigid end of the impedance tube [12]. The sound pressure at microphone 1,2,3, and 4 can be expressed as Eq. (1) to (4) respectively.

$$
\begin{aligned}
& P_{1}=A e^{j\left(\omega t-k x_{1}\right)}+B e^{j\left(\omega t-k x_{1}\right)} \\
& P_{2}=A e^{j\left(\omega t-k x_{2}\right)}+B e^{j\left(\omega t-k x_{2}\right)} \\
& P_{3}=C e^{j\left(\omega t-k x_{3}\right)}+D e^{j\left(\omega t-k x_{3}\right)} \\
& P_{4}=C e^{j\left(\omega t-k x_{4}\right)}+D e^{j\left(\omega t-k x_{4}\right)}
\end{aligned}
$$

where A to D are amplitudes of the sound waves and $k$ is the wave number. $x_{1}$ to $x_{4}$ are the distance between the specimen with the respected microphone 1 to 4 as shown in Figure 1.

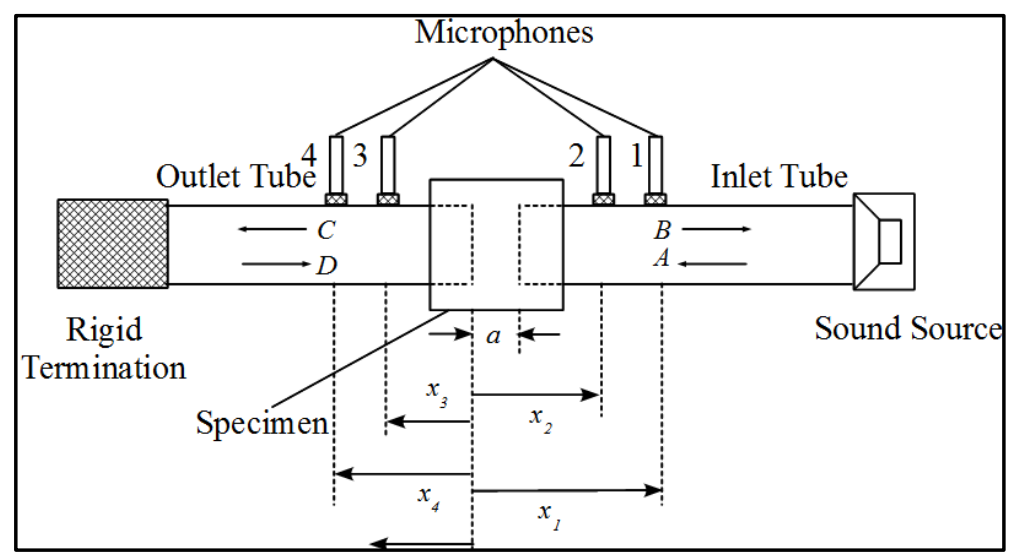

Figure 1. Two-load method of STL measurement. 
The amplitudes of a sound wave can be expressed in terms of the sound pressures $-\mathrm{P}_{1}, \mathrm{P}_{2}, \mathrm{P}_{3}$, and $\mathrm{P}_{4}$ for the 4 microphones and shown as Eq. (5) to (8). The STL coefficient, $\alpha$ can be determined using the Eq. (9).

$$
\begin{aligned}
& A=\frac{j\left(P_{1} e^{j k x_{2}}-P_{2} e^{j k x_{1}}\right)}{2 \sin k\left(x_{1}-x_{2}\right)} \\
& B=\frac{j\left(P_{2} e^{-j k x_{1}}-P_{1} e^{-j k x_{2}}\right)}{2 \sin k\left(x_{1}-x_{2}\right)} \\
& C=\frac{j\left(P_{3} e^{j k x_{4}}-P_{4} e^{j k x_{3}}\right)}{2 \sin k\left(x_{3}-x_{4}\right)} \\
& D=\frac{j\left(P_{4} e^{-j k x_{3}}-P_{3} e^{-j k x_{4}}\right)}{2 \sin k\left(x_{3}-x_{4}\right)} \\
& \left\{\begin{array}{ll}
A \\
B
\end{array}\right\}=\left[\begin{array}{ll}
\alpha & \beta \\
\gamma & \delta
\end{array}\right]\left\{\begin{array}{l}
C \\
D
\end{array}\right\}
\end{aligned}
$$

For the two-load method, two different conditions of the test were conducted, which are rigid cap terminating and open terminating [13]. Solved the equations together and the sound transmission loss coefficient, $\alpha$ is

$$
\alpha=\frac{\mathrm{A}_{1} \mathrm{D}_{2}-\mathrm{A}_{2} \mathrm{D}_{1}}{\mathrm{C}_{1} \mathrm{D}_{2}-\mathrm{C}_{2} \mathrm{D}_{1}}
$$

and the equation for STL in $\mathrm{dB}$ is

$$
\mathrm{STL}=-20 \log (\|\alpha\|)
$$

\section{Materials Selection}

In this study, there are four different building materials chosen, which are autoclaved aerated concrete (AAC) [14-15], expanded polystyrene [16-17], rockwool [18-20], and laminated glass [21-23]. In general, the four materials that choose in this study are normally applied for buildings or constructions. For example, AAC is used to build the structure of building [24-25]; laminated glass is used for the window [26]. These four materials are shown in Figure 2(a) - 2(d). All of the materials are cut into a cylinder shape with the diameter of $30 \mathrm{~mm}$ and the thickness of $10 \mathrm{~mm}$ and $20 \mathrm{~mm}$. 


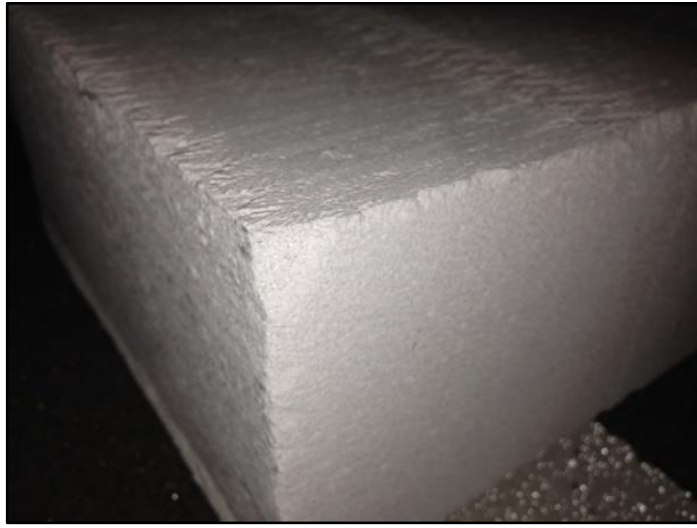

(a)

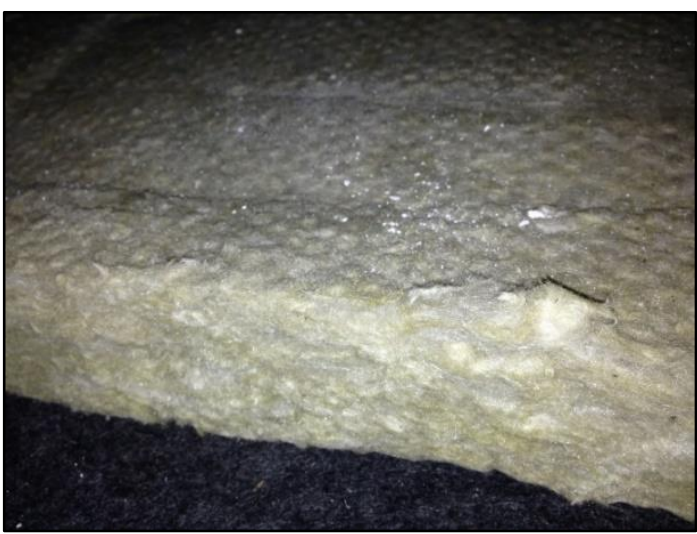

(c)

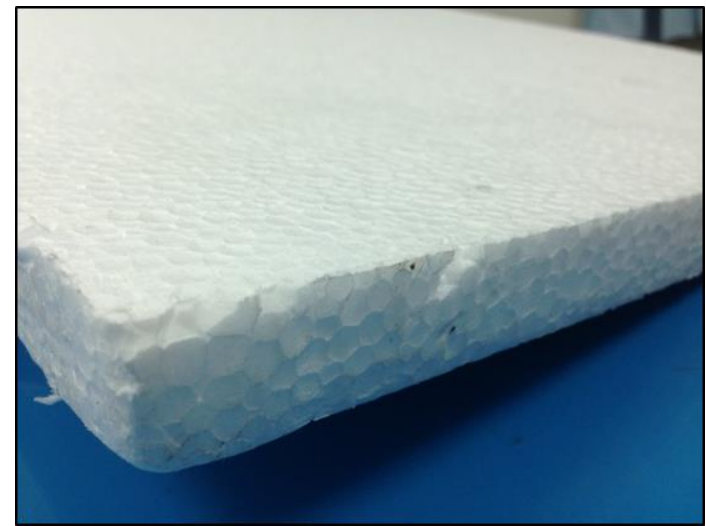

(b)

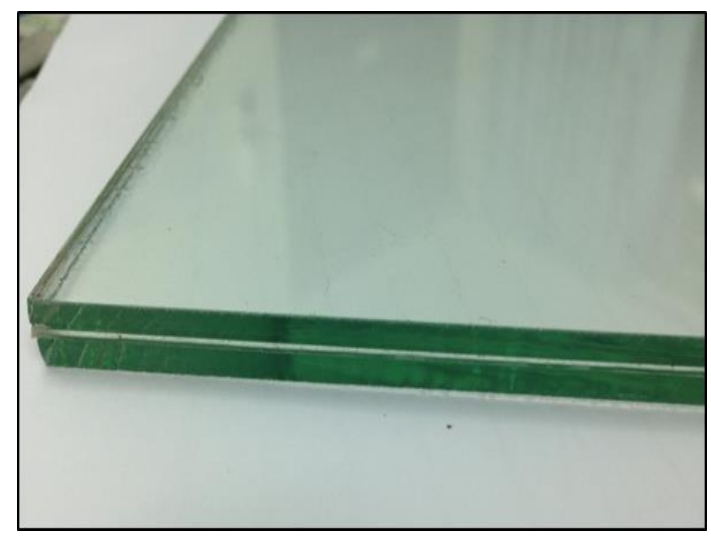

(d)

Figure 2. Building materials (a) autoclaved aerated concrete (AAC); (b) expanded polystyrene; (c) rockwool; (d) laminated glass.

\section{Experiment Setup}

In this study, two-load method impedance tube was used for the sound transmission loss (STL) measurement for the building materials. Figure 3 shows the experimental setup in the laboratory. The two-load method impedance tube setup was built according to ASTM E1050 [27]. There are two pairs of microphones before and after the specimen is mounted on the main tube. The $1 / 2$ inch BSWA MA211 microphones were used in this measurement. It was calibrated with CENTER 326 sound level calibrator before the STL measurement was conducted. The main tube is made of acrylic and in the shape of a cylinder, with a diameter of $30 \mathrm{~mm}$ and $3 \mathrm{~mm}$ wall thickness.

In Figure 3, one end of the main tube is connected to the sound source (speaker box) driven by the output signal generator of LMS SCADAS Mobile SCM01. The random noise containing the frequencies of $125 \mathrm{~Hz}$ to $5500 \mathrm{~Hz}$ is used for the noise source. The other end of the main tube is terminated with the rigid or anechoic termination. The signals from the four microphones are collected by the data acquisition board of LMS SCADAS Mobile SCM01 and then processed by the analyser software. 


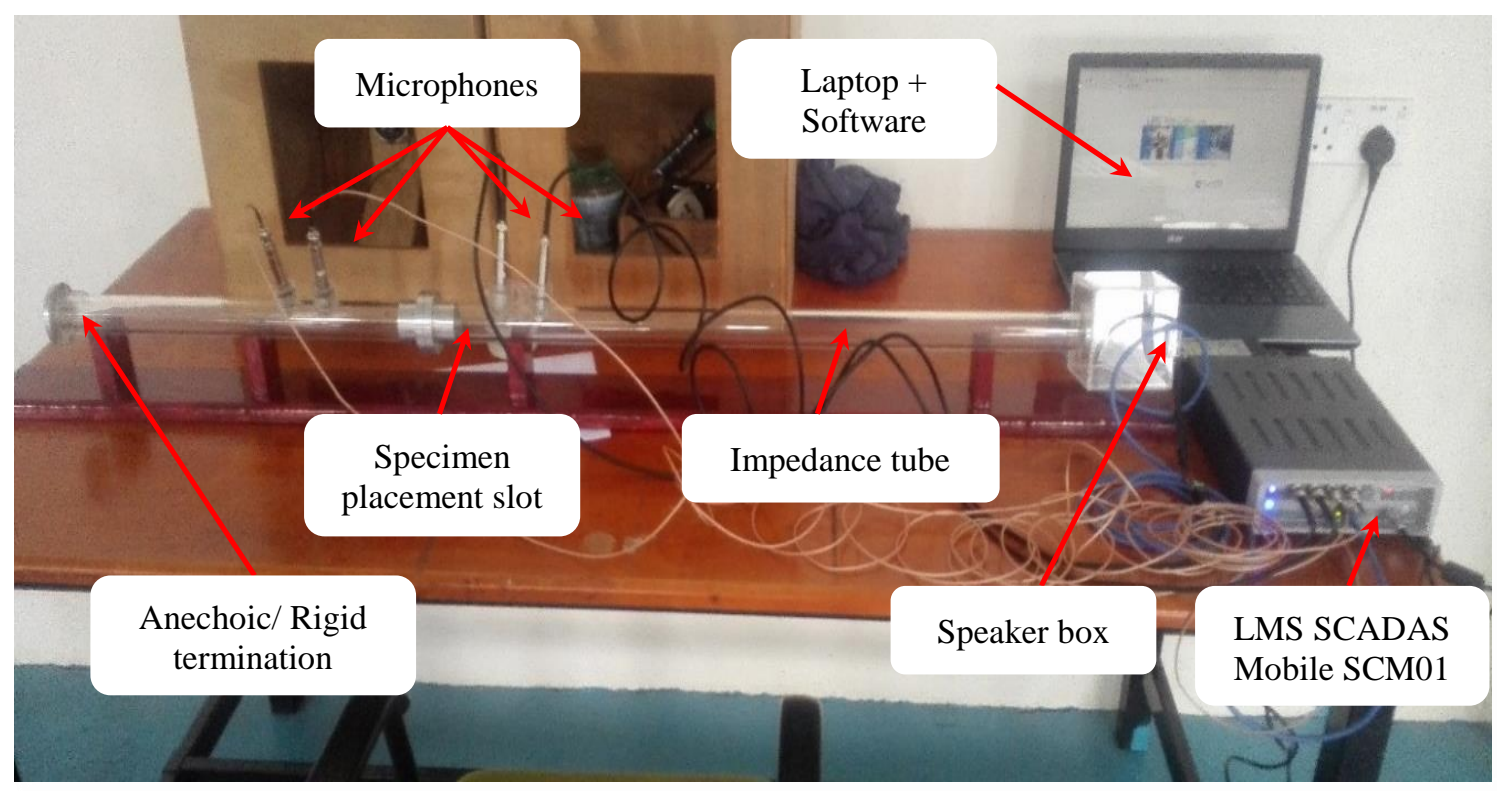

Figure 3. Two-load method impedance tube experimental setup.

\section{RESULTS AND DISCUSSION}

\section{Sound Transmission Loss (STL) of Building Materials}

The sound transmission loss (STL) of autoclaved aerated concrete (AAC) is shown in Figure 4(a). The result indicates specimen with $20 \mathrm{~mm}$ thickness has higher STL compared with $10 \mathrm{~mm}$ thickness specimen. The STL of AAC is greatest in the frequency range of $3000-5000 \mathrm{~Hz}$. From frequency $3000-5500 \mathrm{~Hz}$, the STL for both $10 \mathrm{~mm}$ and $20 \mathrm{~mm}$ specimens are considered fluctuate. Frequency range from $200-3000 \mathrm{~Hz}$, the STL of $10 \mathrm{~mm}$ specimen is steadily increasing to $7 \mathrm{~dB}$ where $20 \mathrm{~mm}$ specimen is increased to $8 \mathrm{~dB}$ at $1300 \mathrm{~Hz}$ and decreases slowly until $3000 \mathrm{~Hz}$. The peak value for both lines are fell in the frequency of $3360 \mathrm{~Hz}$. The peak value of STL for $10 \mathrm{~mm}$ specimen is $69.6 \mathrm{~dB}$, which is higher than $20 \mathrm{~mm}$ specimen with the STL peak value of $68.5 \mathrm{~dB}$. The different in the peak value is less than $1 \mathrm{~dB}$.

Figure 4(b) shows the STL result of expanded polystyrene. It is found that $20 \mathrm{~mm}$ thickness specimen also has greater STL compared to $10 \mathrm{~mm}$ thickness specimen, which similar trend compared with AAC. For frequency range of $200-3000 \mathrm{~Hz}$, the $10 \mathrm{~mm}$ specimen is steady with a low STL, and start fluctuating in the frequency range of 3000 $-5500 \mathrm{~Hz}$. Specimen with thickness $10 \mathrm{~mm}$ reaches the highest STL of $64.6 \mathrm{~dB}$ at 3360 $\mathrm{Hz}$. The $20 \mathrm{~mm}$ thickness specimen is fluttered from $200-5500 \mathrm{~Hz}$. It is observed that there are four STL peaks, which drop at $1210 \mathrm{~Hz}, 2630 \mathrm{~Hz}, 3360 \mathrm{~Hz}$ and $4540 \mathrm{~Hz}$, with the STL of $49.6 \mathrm{~dB}, 20.1 \mathrm{~dB}, 74.1 \mathrm{~dB}$ and $31.3 \mathrm{~dB}$ respectively. Both of the specimens reached the highest STL at frequency $3333 \mathrm{~Hz}$. By the observation as depicted in Figure 4(b), expanded polystyrene specimen has shown it could deliver much more improvement of STL compared to others selected materials in this study for the frequency below 3300 $\mathrm{Hz}$, as its thickness was increased from $10 \mathrm{~mm}$ to $20 \mathrm{~mm}$. 


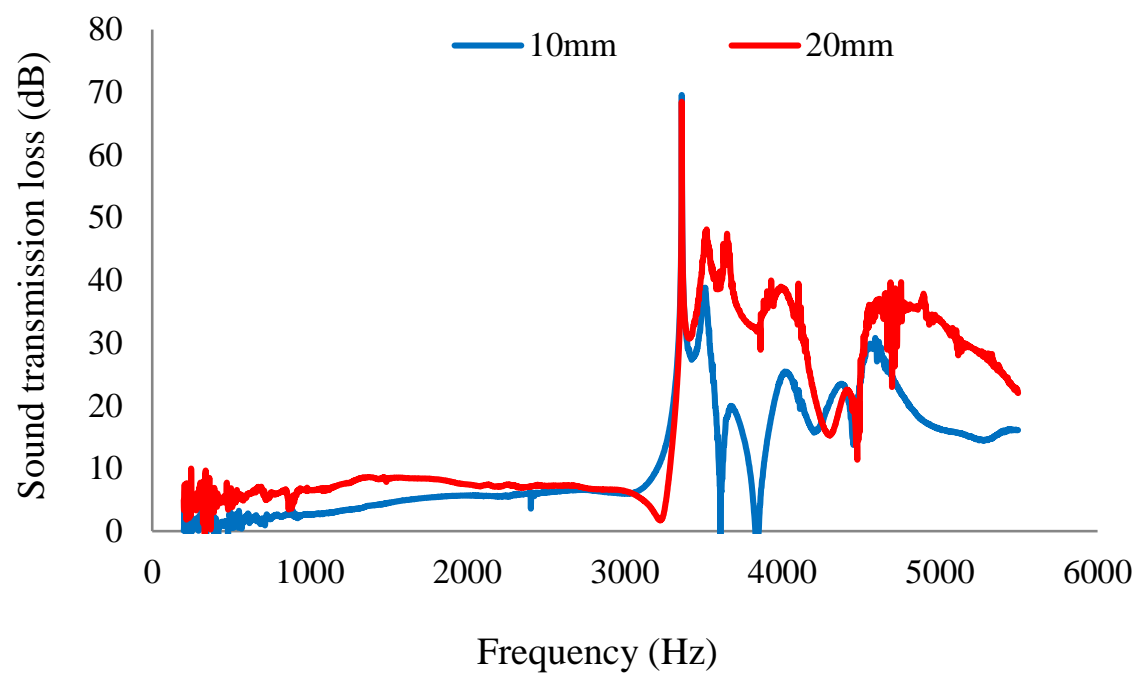

(a)

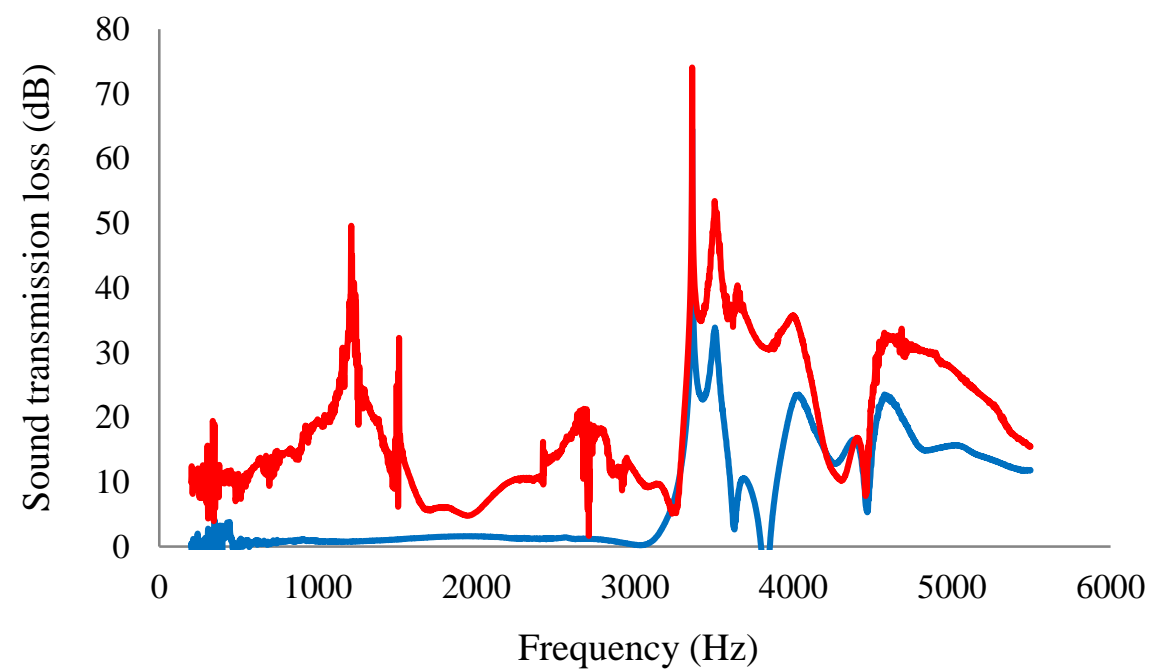

(b)

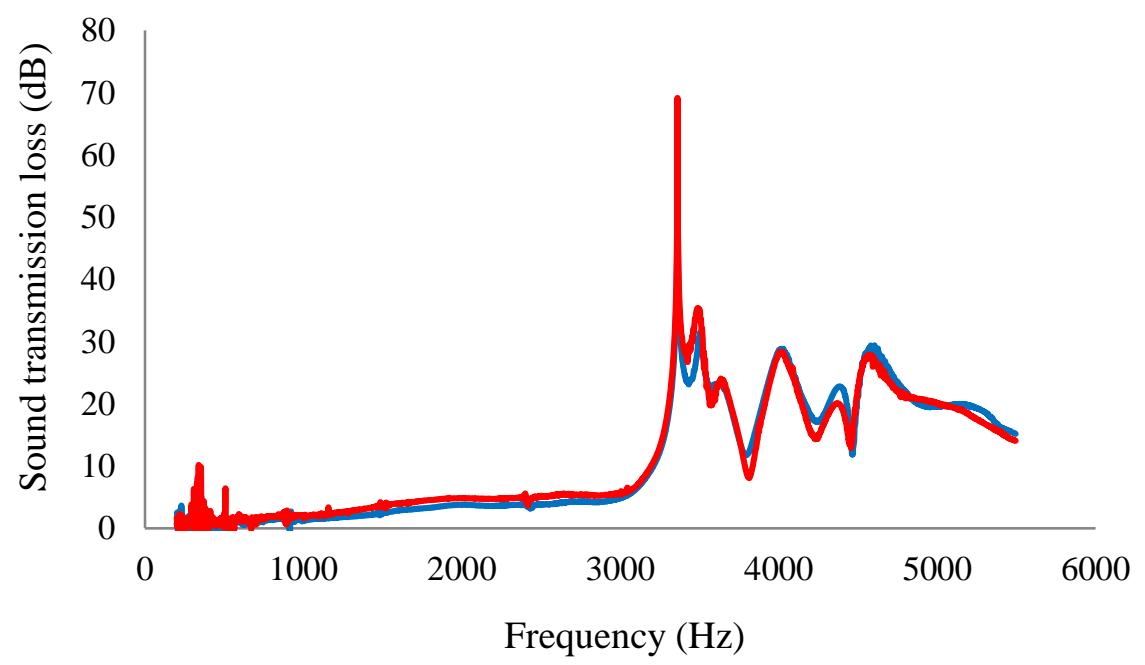

(c) 


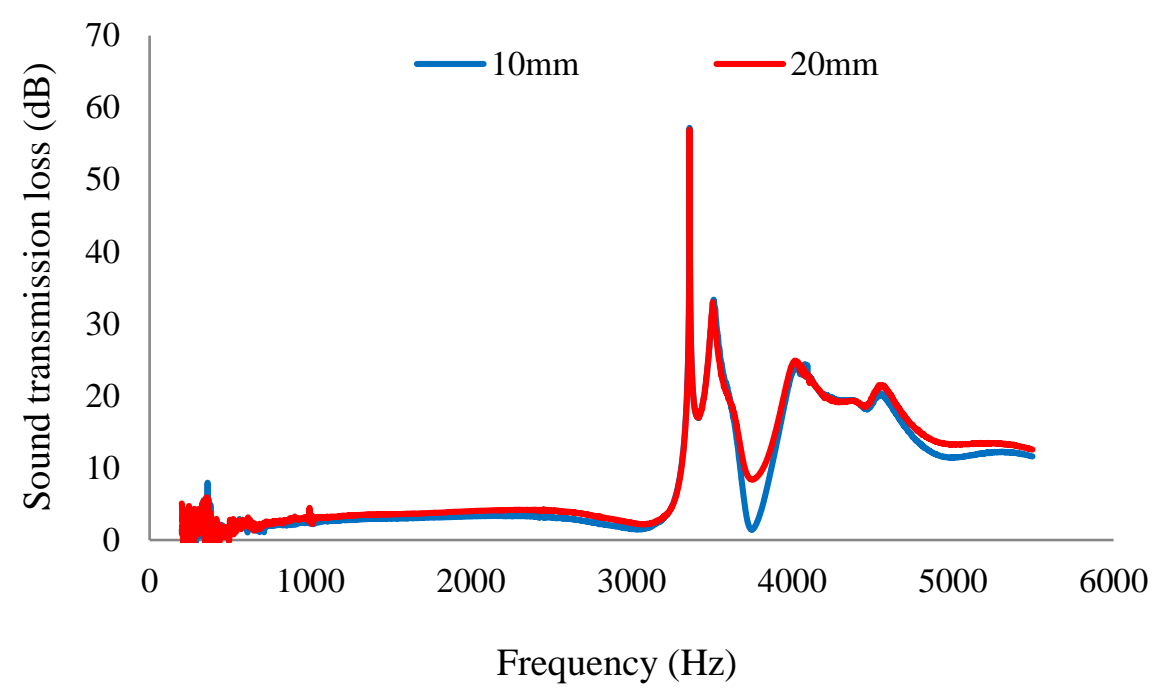

(d)

Figure 4. Sound transmission loss of (a) AAC (b) expanded polystyrene, (c) laminated glass and; (d) rockwool.

Figure 4(c) shows the STL of laminated glass for the specimen thickness of 10 $\mathrm{mm}$ and $20 \mathrm{~mm}$. It is observed that the STL curve for the $10 \mathrm{~mm}$ and $20 \mathrm{~mm}$ specimens are quite close to each others. Both the specimens have the steady STL for the frequency range of $200-3000 \mathrm{~Hz}$ and fluctuate at a higher frequency range of $3000-5500 \mathrm{~Hz}$. Both of the specimens have the STL peak at the same frequency but different value, which is $69.2 \mathrm{~dB}$ for $20 \mathrm{~mm}$ thickness specimen and $66.9 \mathrm{~dB}$ for the $10 \mathrm{~mm}$ thickness specimen. Even Figure 4(c) shows both specimens have almost similar STL, however in overall, 20 $\mathrm{mm}$ thickness specimen has greater STL compared to the $10 \mathrm{~mm}$ specimen. Based on the observation in this section, laminated glass can be considered that it has insignificant effect of the thickness on the STL improvement.

STL for the rockwool specimen is shown in Figure 4(d). The STL results of rockwool for specimens in $10 \mathrm{~mm}$ and $20 \mathrm{~mm}$ thickness are almost the same STL result. However, the $20 \mathrm{~mm}$ specimen is showed greater STL compared to $10 \mathrm{~mm}$ specimen in overall. Figure 4(d) shows both specimens are steady, and low STL at the frequency range $200-3000 \mathrm{~Hz}$, and the STL curve fluctuated at frequency $3000-5500 \mathrm{~Hz}$. At the same time, it is also found that the STL peaks for both specimens are dropping at the same frequency of $3332 \mathrm{~Hz}$ and similar STL of $57 \mathrm{~dB}$. The STL of rockwool is considered relatively low compared with others selected materials in this study. This phenomenon can be explained by the empirical mass law, where the STL is directly proportional to the surface density of the materials [4].

\section{Comparison of Sound Transmission Loss between Different Building Materials}

In this section, the STL comparison of four building materials with $10 \mathrm{~mm}$ and $20 \mathrm{~mm}$ thickness are shown in Figure 5(a) and Figure 5(b) respectively. For the specimen thickness $20 \mathrm{~mm}$, the STL of four building materials show similar inflation trend. At the frequency range of $200-3000 \mathrm{~Hz}$, all the building materials are showing low and steady STL. For this frequency range, AAC scores the highest STL. On the other hand, STL is fluctuating at the frequency range $300-5500 \mathrm{~Hz}$. In overall, all the building materials 
score the STL peak value at the frequency of $3332 \mathrm{~Hz}$. The differences in the STL of these four materials are very close for $10 \mathrm{~mm}$ thickness of the specimen.

In Figure 5(b), it shows that mostly the building materials have steady and low STL at frequency $200-3000 \mathrm{~Hz}$. However, the expanded polystyrene has a fluttered trend of STL in overall. All the building materials achieve the STL peak at the frequency $3332 \mathrm{~Hz}$, where expanded polystyrene scores the highest STL of $75 \mathrm{~dB}$. In general, expanded polystyrene delivers the greatest STL compared to the others, and rockwool has the lowest STL for the specimen thickness of $20 \mathrm{~mm}$.

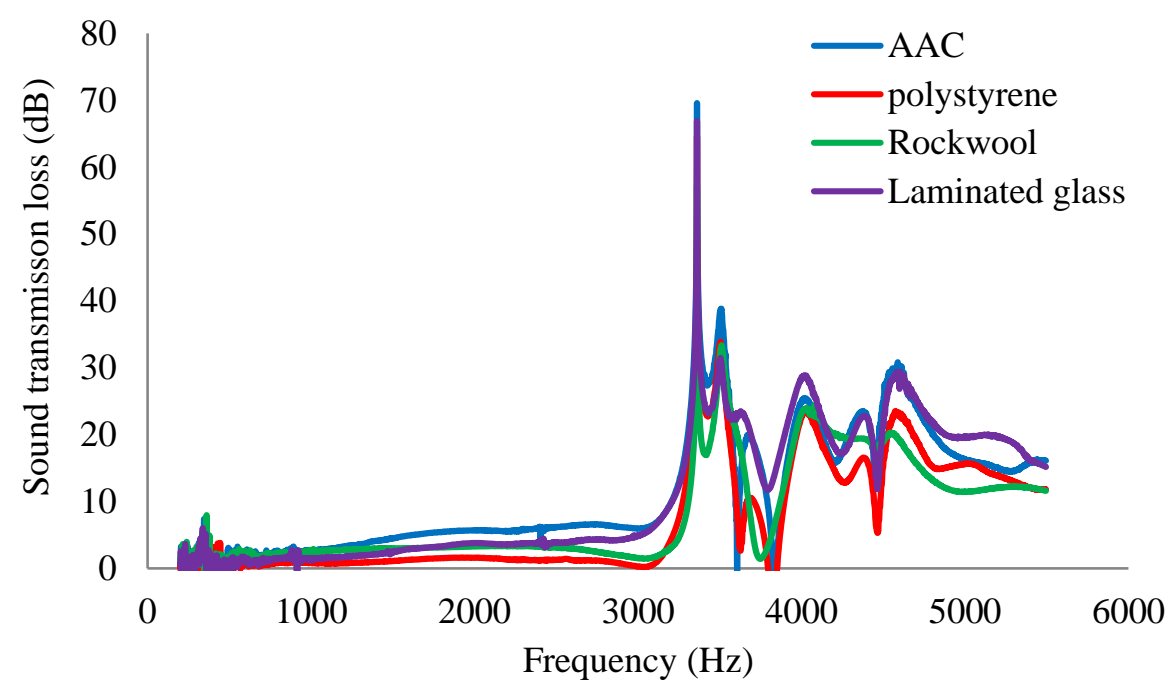

(a)

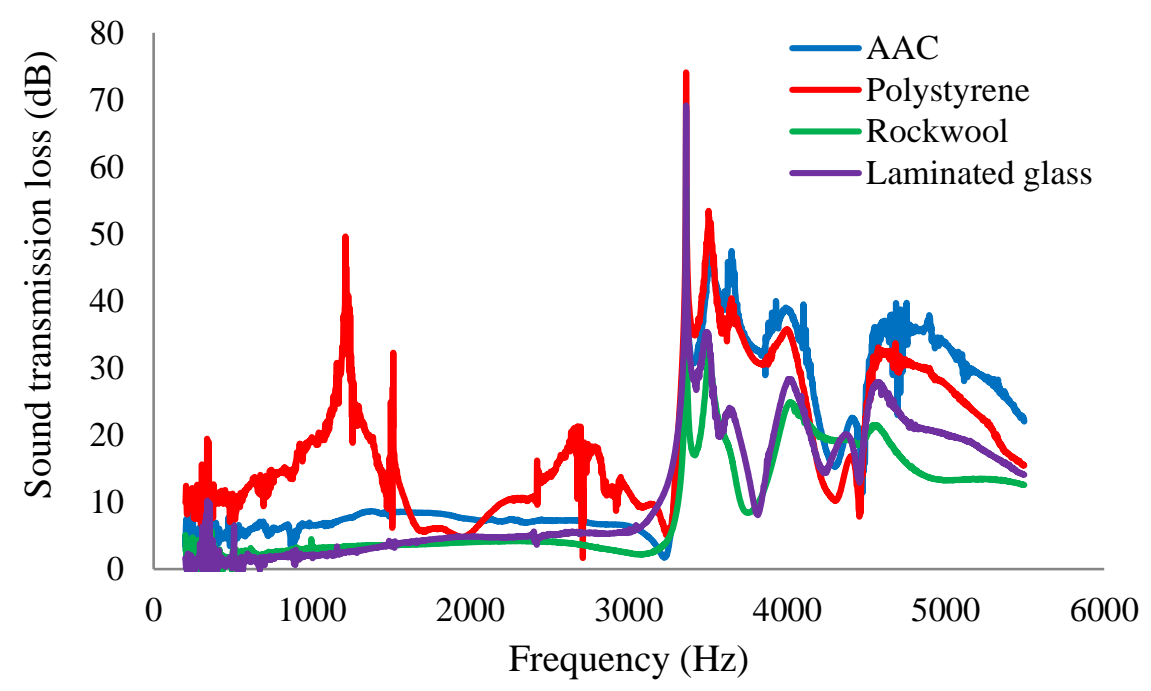

(b)

Figure 5. Sound transmission loss of four building material specimens in (a) $10 \mathrm{~mm}$ and; (b) $20 \mathrm{~mm}$ thickness.

\section{Sound Transmission Loss Different Combination of Building Materials}

There are six combinations of building materials are selected to investigate and compare the sound transmission loss (STL) performance in this section. The six combinations 
include AAC \& laminated glass, AAC \& rockwool, AAC \& polystyrene, rockwool \& laminated glass, rockwool \& polystyrene, and polystyrene \& laminated glass. The STL results of different building materials combination are shown in Figure 6.

Most of the combinations show transient and low STL at the frequency range of $200-3000 \mathrm{~Hz}$ except the AAC \& expanded polystyrene combination which fluttered at the frequency $200 \mathrm{~Hz}-1500 \mathrm{~Hz}$. All the building materials combinations have the similar zig-zagged trend at frequency $3000-5500 \mathrm{~Hz}$ except AAC \& expanded polystyrene combination. Based on Figure 12, AAC \& expanded polystyrene combination consists of two STL peaks compared to the others combinations. The first STL peak is dropped at $3332 \mathrm{~Hz}$ as the others combined, the second peak is located at $3769 \mathrm{~Hz}$. The STL value of the first peak and second peak for the AAC \& expanded polystyrene combination are $81 \mathrm{~dB}$ and $77 \mathrm{~dB}$ respectively. The results also show that the AAC \& expanded polystyrene combination is considered the optimum performance combination which delivers the highest STL among the selected combinations in this study.

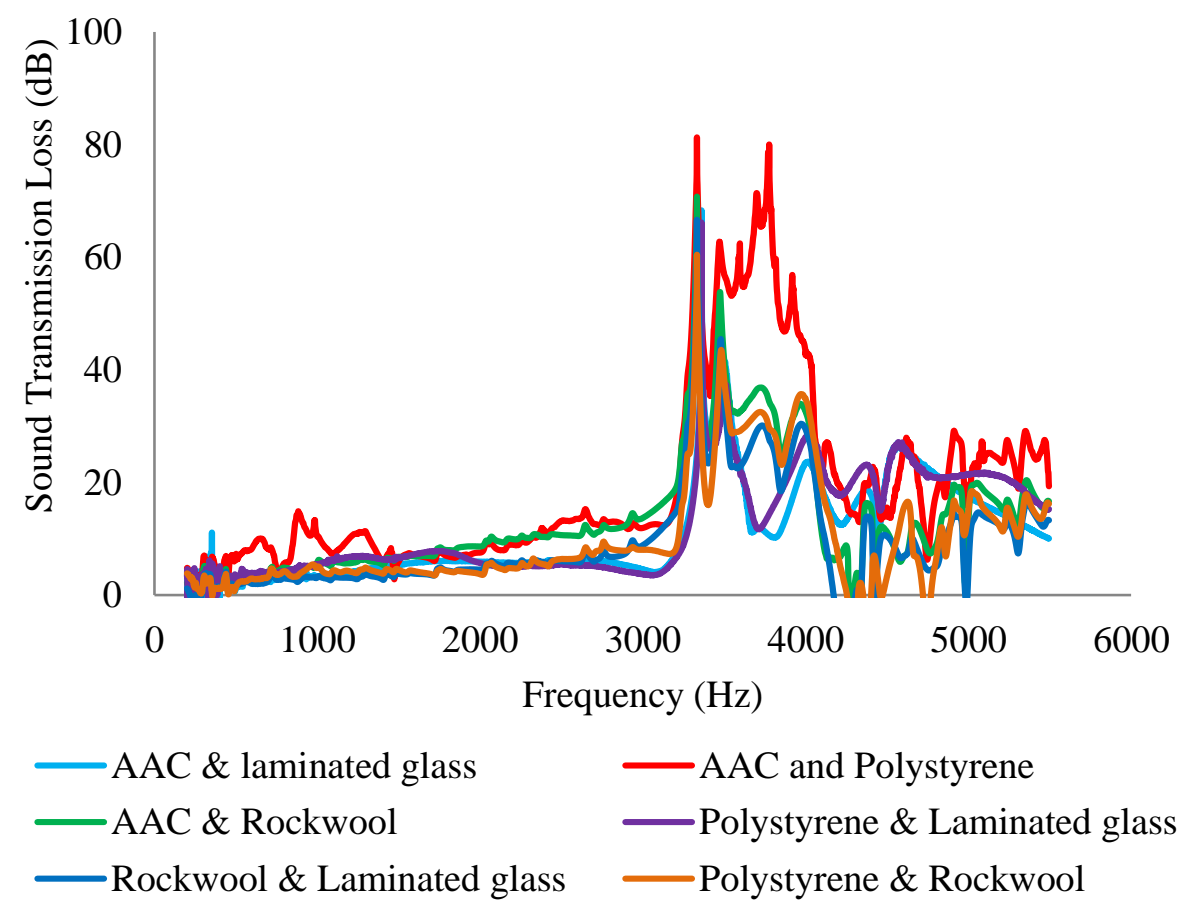

Figure 6. Sound transmission loss of different combination of building materials.

\section{CONCLUSION}

In this study, it is found that AAC is considered the greatest sound insulator among the four materials chosen to investigate as AAC scores the highest sound transmission loss (STL) for $10 \mathrm{~mm}$ and $20 \mathrm{~mm}$ specimen thickness. According to the empirical mass law, the laminated glass should be the best sound insulation materials; however the STL investigation in this study does not comply it and it may need to do further clarification in the next study.

The combination building materials effect also has been determined in this study. Based on the STL results for the different combination of the building materials, it shows clearly that AAC \& expanded polystyrene combination is the best for sound insulation. The combination effect is considered better than only one type of material for the same 
thickness. By lining the expanded polystyrene on the building wall built from AAC, it is expected that sound insulation performance will be very significant and effective.

\section{ACKNOWLEDGEMENT}

The authors are very thankful to the Solid Mechanics \& Vibration Laboratory technicians - Mr Muhamad Aliff who always available to provide technical support in this study. The authors also very grateful to Dr Ooi Lu Ean and Mr Wan Amri, who come from the School of Mechanical Engineering, Universiti Sains Malaysia (USM) to guide the authors throughout the data collection process.

\section{REFERENCES}

[1] Asdrubali F. Survey on the acoustical properties of new sustainable materials for noise control. In: Proceedings of Euronoise 2006, Tampere, Finland; 30 May-1 Jun, 2006.

[2] Freiheit R, Neal MT. Architectural acoustics: From concert halls to classrooms. The Journal of the Acoustical Society of America. 2018; 143(3):1735.

[3] Hassan OA. Building acoustics and vibration: theory and practice. Singapore:World Scientific Publishing Company; 2009.

[4] Ballou G. Handbook for sound engineers. 5th ed. Oxford:Focal Press; 2015.

[5] Raichel DR. The science and applications of acoustics. Springer Science \& Business Media; 2006.

[6] Amares S, Sujatmika E, Tan WH, Durairaj R, Hamid HS. A Review: Characteristics of Noise Absorption Material. Journal of Physics: Conference Series. 2017; 908(1):1-9.

[7] Morillas JM, Gozalo GR, González DM, Moraga PA, Vílchez-Gómez R. Noise pollution and urban planning. Current Pollution Reports. 2018:1-2.

[8] Rathi O, Khandve PV. Cost effectiveness of using AAC blocks for building construction in residential building and public buildings. International Journal of Research in Engineering and Technology. 2016; 5(05):517-520.

[9] Szudrowicz B, Sytek GZ, GĊbarowski P. Sound insulation performance of aerated concrete walls. Retrieved from http://gazobeton.org/sites/default/files/sites/all/uploads/sound_insulation_perfor mance_of_aerated_concrete_walls.pdf; 12 September, 2018.

[10] Brelak S, Dachowski R. Effect of Autoclaved Aerated Concrete Modification with High-Impact Polystyrene on Sound Insulation. IOP Conference Series: Materials Science and Engineering. 2017; 245(2):1-5.

[11] Hamad AJ. Materials, production, properties and application of aerated lightweight concrete. International journal of materials science and engineering. 2014; 2(2):152-157.

[12] Hua X, Herrin DW. Practical considerations when using the two-load method to determine the transmission loss of mufflers and silencers. SAE International Journal of Passenger Cars-Mechanical Systems. 2013; 6:1094-1101.

[13] Yousefzadeh B, Mahjoob M, Mohammadi N, Shahsavari A. An experimental study of sound transmission loss (STL) measurement techniques using an impedance tube. Journal of the Acoustical Society of America. 2008; 123(5):1715-1718. 
[14] Juan R. All About Autoclaved Aerated Concrete (AAC). Retrieved from https://www.thebalancesmb.com/what-is-autoclaved-aerated-concrete-844759; 12 September, 2018.

[15] Portland Cement Association. Autoclaved Aerated Concrete. Retrieved from https://www.cement.org/cement-concrete-applications/paving/buildingsstructures/concrete-homes/building-systems-for-every-need/autoclaved-aeratedconcrete; 12 September, 2018.

[16] Akbari B, Bagheri R. Deformation behavior and mechanical properties of polystyrene/organoclay/SEBS. Mechanics of Materials. 2016;103:11-7.

[17] Mohajerani A, Ashdown M, Abdihashi L, Nazem M. Expanded polystyrene geofoam in pavement construction. Construction and Building Materials. 2017;157:438-48.

[18] Bussell WT, McKennie S. Rockwool in horticulture, and its importance and sustainable use in New Zealand. New Zealand journal of crop and horticultural science. 2004;32(1):29-37.

[19] Menon S, Naranje VG. Experimental investigation of recycling of rock-wool insulation as insulator in concrete blocks. International Journal of Engineering and Applied Sciences. 2017;4(4):71-74.

[20] Nick G. Rockwool. Retrieved from https://www.nachi.org/rockwool.htm; 12 September, 2018.

[21] Zang MY, Chen SH. Laminated Glass. M.A. thesis, South China University of Technology, China, 2011.

[22] Vedrtnam A, Pawar SJ. Laminated plate theories and fracture of laminated glass plate-a review. Engineering Fracture Mechanics. 2017;186:316-330.

[23] Lansing M. The advantages and disadvantages of using laminated glass windows. Retrieved from https://yourhomesecuritywatch.com/advantages-disadvantagesusing-laminated-glass-windows/; 12 September, 2018.

[24] Drochytka R, Zach J, Korjenic A, Hroudová J. Improving the energy efficiency in buildings while reducing the waste using autoclaved aerated concrete made from power industry waste. Energy and Buildings. 2013; 58:319-323.

[25] Jerman M, Keppert M, Výborný J, Černý R. Hygric thermal and durability properties of autoclaved aerated concrete. Construction and building materials. 2013; 41:352-359.

[26] Zhang X, Hao H, Ma G. Laboratory test and numerical simulation of laminated glass window vulnerability to debris impact. International Journal of Impact Engineering. 2013; 55:49-62.

[27] ASTM E. 1050-90. Standard test method for impedance and absorption of acoustical materials using a tube, two microphones, and a digital frequency analysis system. American Society for Testing and Materials, Philadelphia, PA. 1998. 